\title{
A Framework for Assessing the Pedagogical Effectiveness of Wiki-Based Collaborative Writing: Results and Implications
}

\author{
Said Hadjerrouit \\ University of Agder, Kristiansand, Norway
}

Said.Hadjerrouit@uia.no

\begin{abstract}
Due to the new possibilities they open up for collaborative writing in education, wikis have received much attention the last few years. As a result, teachers have used wikis to achieve various educational purposes, such as wikis for online courses, teacher evaluation, or class project. However, the novelty and popularity of a technology do not automatically imply its suitability in educational settings. To evaluate the pedagogical effectiveness of wiki-based collaborative writing, there is a need for a theoretical framework that focuses on three essential elements of wikis and their relationships: technology, content, and group work. The framework was used to assess students' perceptions of wiki-based collaborative writing. Even though the results achieved so far are not as satisfactory as expected, the framework provides a promising way of looking at collaborative writing activities in a wiki-based environment. Based, on the results, the article reports on pedagogical implications of using wikis as collaborative writing tools in teacher education.
\end{abstract}

Keywords: Collaborative learning, collaborative writing, content, MediaWiki, pedagogy, technology, wiki.

\section{Introduction}

Wikis are considered as Web 2.0 technologies that promote collaborative learning, social interaction, and information sharing. Accordingly, wikis in teacher education are used to achieve various educational goals by means of collaborative learning, group interactions, and sharing of good practice examples of wiki (Austin, Smyth, Rickard, Quirk-Bolt, \& Metcalfe, 2010; Deters, Cuthrell, \& Stapleton, 2010; Hadjerrouit, 2012a; Honegger, 2005; Mindel \& Verma, 2006; Parker \& Chao, 2007; Witney \& Smallbone, 2011). As for any digital technology, the integration of wikis into teacher education requires the consideration of a number of essential elements (Mishra \& Koehler, 2006). These are wiki technology, wiki content, and group work. Wiki tech-

Material published as part of this publication, either on-line or in print, is copyrighted by the Informing Science Institute. Permission to make digital or paper copy of part or all of these works for personal or classroom use is granted without fee provided that the copies are not made or distributed for profit or commercial advantage AND that copies 1) bear this notice in full and 2) give the full citation on the first page. It is permissible to abstract these works so long as credit is given. To copy in all other cases or to republish or to post on a server or to redistribute to lists requires specific permission and payment of a fee. Contact Publisher@InformingScience.org to request redistribution permission. nology provides potentially new functionalities to generate content associated with a specific topic. To produce the wiki content collaboratively, students are required to work in groups. Students also need to be knowledgeable in the wiki topic to be produced by means of wiki technology and group work. Moreover, wiki-based collaborative writing requires a thoughtful understanding of the complex relationships between wiki technology, wiki content, and group work. To 
address these issues, there is a need for a theoretical framework that offers a new way of looking at wiki-based collaborative writing in teacher education. Based on the framework, the main purpose of this article is to report on a study that investigates students' perceptions of wiki-based collaborative writing in teacher education by means of self- and peer-assessment. The work also reports on pedagogical implications of using wikis as collaborative writing tools. Finally, the article suggests a pedagogy that suits the specificities of wikis in teacher education. This study draws on similar research done previously (Hadjerrouit, 2012a, 2012b, 2012c; Hadjerrouit 2013).

The paper is structured as follows. First, the research questions are stated. Second, the theoretical framework is described, followed by a literature review. Then, the case study is presented. The next section describes the results, followed by a discussion of pedagogical implications of using wikis in teacher education. Finally, the paper suggests a wiki pedagogy that facilitates collaborative writing.

\section{Research Questions}

The following research questions guided this work:

1) What are the key elements of wikis in teacher education, and how are they connected to each other?

2) How do students perceive the key elements of wikis and their relationships when they carry out collaborative writing activities?

3) Which pedagogical implications can be drawn from the students' perceptions of collaborative writing?

To answer the first question, a theoretical framework is developed to capture the main elements of wikis in teacher education. A case study is used to answer the second question. The study uses self- and peer-assessment to analyse students' perceptions of wiki-based collaborative writing. Finally, to address the third research question, the results are analysed in terms of the theoretical framework and related research work, resulting in the specification of a wiki pedagogy that fosters collaborative writing.

\section{Literature Review}

Wikis are considered as Web 2.0 technologies that enable users to edit and publish content on the Web. Wiki tools are supposed to have a user-friendly and intuitive user interface that does not require much training (Lamb, 2004; Tetard, Patokorpi, \& Packalen, 2009). However, research has raised a number of shortcomings regarding the technical capabilities of wikis. One of the most important drawbacks is the lack of a WYSIWYG editor that facilitates editing and designing (Thomas, King, \& Minocha, 2009). Likewise, Harsell (2010) indicated that students still stress the need for technical training, because they do not possess pre-requisite knowledge for using wikis. Similarly, Jones (2010) pointed out that technical problems still constitute sources of frustration for some students.

In addition to their supposed simplicity and ease-of-use, wikis are considered as tools that foster collaborative writing, because they provide support for the writing process and revisions by means of the history function that tracks all versions of the wiki. However, Pifarre and Fischer (2011) indicated that there are still are relatively few research reports that show successful collaborative writing, and that relying too much on wiki affordances does not always work. Furthermore, Huang and Nakazawa (2010) argued that learners are not accustomed to the wiki way of collaboration. Therefore, teachers need to sustain learners' wiki activities throughout a learning process. Likewise, researchers pointed out that students use wiki more co-operatively than collaboratively, by dividing up the tasks at the outset and then later assembling the separate parts of 
the tasks (Tay \& Allen, 2011; Witney \& Smallbone, 2011). This way of working clearly limits the creation of shared knowledge. Also L. Grant (2009) found that collaborative practices are not evident when using wiki. Rather, students seemed to import practices of individualized written assessment. Other challenging aspects of collaboration are the purpose and nature of collaboration, the different levels of interaction, as well as competition and cooperation in collaborative learning (Austin et al., 2010).

Wikis have a discussion page to support reflections and negotiations on issues related to the wiki content and technicalities of the tool being used. However, Witney and Smallbone (2011) reported that face-to-face meetings were the students' preferred means of facilitating group work and discussion. In addition to oral communication, students also use other tools (email, Google Docs, Skype, mobile phone, etc.) in combination with wikis when they process collaborative activities. As a result, Huang and Nakazawa (2010) suggest limiting students' access to other tools as a prerequisite to create an authentic wiki-based learning environment.

Caple and Bogle (2013) mentioned additional two factors that impact collaboration: time and assessment. Students need to be given more time to familiarise themselves with wikis, because collaboration among students is demanding and time-consuming. Likewise, assessment is important to evaluate students' individual contributions to collaborative writing (Tetard et al., 2009). Furthermore, Caple and Bogle (2013) pointed out that wikis need to be customised to the specific needs of the users, as part of a virtual community, where members have access to the wiki. Similarly, Ng and Lai $(2012$, p. 80) indicated that content "was the most common criterion used for assessing the wiki projects".

Considering that several factors influence wiki-based collaborative writing, e.g., wiki technology, content, group work, time, assessment, and user involvement, researchers suggest that it is the pedagogical approach to wiki that leads to collaboration, not the technology itself (Cole, 2009; Tay \& Allen, 2011; Witney \& Smallbone, 2011).

\section{Theoretical Framework}

To evaluate students' perceptions of wiki-based collaborative writing, it is important to clarify the very nature of collaborative learning and writing. Furthermore, there is a need for a theoretical framework that brings to the fore essential elements of wikis and their relationships. Then, a set of criteria are derived from these elements to assist teacher in evaluating students' perceptions of wiki-based collaborative writing in teacher education.

\section{Collaborative Learning and Writing in Education}

Collaborative learning can be defined as a type of activity that takes place in student groups for the purpose of achieving an educational goal (Guerrero, Mejías, Collazosi, Pino, \& Ochoa, 2003). Collaborative learning is rooted in Vygotsky's socio-cultural theory which assumes that learning is a result of social interactions where language plays an essential role. According to Vygotsky (1978, p. 86), learning occurs in the zone of proximal development (ZPD), defined as "the distance between the actual developmental level as determined by independent problem solving and the level of potential development as determined through problem solving under adult guidance, or in collaboration with more capable peers." In addition to teacher-student and expert-novice interactions that can be conceptualized using the concept of ZPD, students' interactions can also be labelled within the ZPD, as they can achieve higher levels of performance than they might do by working independently from each other ( $\mathrm{Li} \& \mathrm{Zhu}, 2013$ ). According to Johnson and Johnson (1985), collaborative learning promotes higher achievement than individual contributions, but it requires a longer time for students to achieve learning goals. Moreover, Nokes-Malach, Meade, and Morrow (2012, p. 37) pointed out that "collaborative success depends critically on the rela- 
tion between the participants' prior domain knowledge, collaborative skill, and the task affordances."

Collaborative learning can be considered as an umbrella term for a variety of educational activities including joint efforts by students, or teachers and students (Goodsell, Mather, \& Tinto, 1992). One of those activities is labelled under the term "collaborative writing". Accordingly, collaborative writing is a learning activity where two or more students work together to produce a joint written document. More precisely, collaborative writing activities are carried out when two or more students modify, revise, and/or review each other's contributions to the document (Farkas, 1991, cited in Witney, \& Smallbone, 2011). Collaborative writing should be distinguished from cooperative writing, where students divide the writing task among themselves, work independently, and then put together individual contributions to a final product (Farkas, 1991, cited in Witney, \& Smallbone, 2011). Collaborative writing can increase student participation, facilitate discussion, enhance critical thinking, and improve document quality (Hernandez et al., 2000). On the other hand, collaborative writing activities may be time consuming and difficult to coordinate. This includes the possibility of copying one another's work, and inhibition about expressing feelings to avoid controversial issues (Hernandez et al, 2000).

\section{Key Elements of Wiki and their Relationships}

Integrating technology into teacher education is a topic of current research. According to Mishra and Koehler (2006), it is about addressing pedagogical knowledge required for technology integration for teaching and learning a given subject or content. Similarly, to capture the very essence of wikis in teacher education, it is necessary to consider the subject content being studied, the wiki functionality needed to design the content, and group work to create the subject content collectively. Accordingly, wikis in teacher education have three essential elements: wiki technology, wiki content, and group work. These elements need to be closely linked to each other for efficient use in teacher education. There are three categories of links:

a. Link between wiki technology and wiki content. Wiki technology is expressed in terms of editing and formatting features, which are used to design comprehensible and useroriented content. The nature of the content affects the way it is designed.

b. Link between wiki technology and group work. Wiki technology includes editing features, tracking versions of the wiki, and group discussion page. These provide support for group work, which, in turn, influence the way wiki technology is used.

c. Link between group work and wiki content. Group work is used to generate the wiki content collectively. Group work strategies consist of collaboration, cooperation, and discussion. In turn, the nature of the content influences the way students work together.

The theoretical framework is founded on these key elements, and their relationships (Figure 1). From a technological point of view, a wiki is a Web 2.0 technology with three main features. Wikis rely on a simplified HTML language to quickly create wiki applications. Wikis have also a discussion page that allows students to reflect on issues related to the wiki topic and functionality. In addition, wikis have a history function that tracks all versions of the wikis, so that it is possible to collect quantitative data on students' contributions to the wiki, including making comparison between two versions of the wiki. A plethora of wiki tools can be used to create wikis in teacher education. MediaWiki was chosen for this purpose, because it incorporates all features described above. In addition, MediaWiki requires user authentication, and it is restricted to university employees and students, making it particularly appropriate for education (Kasemvilas \& Olfman, 2009). Criteria that influence the pedagogical usability of WBLRs are as follows: 
Secondly, wikis are considered as a technology that fosters group work in educational settings. Group work aims at stimulating and facilitating students' communicative skills, collaborative and cooperative ways of working, negotiations, and critical thinking skills as well. The advantages of group work are underpinned by socio-cultural learning principles (Vygotsky, 1978), which assume that learning benefits resulting from group work are greater than the sum of individual work (Witney \& Smallbone, 2011; Yarrow \& Topping, 2001). Using wikis to promote group work as a form of collaborative learning may have great potential in teacher education. Wikis may be used collaboratively by a student team for a joint project or assignment, essay or article. Group work can also benefit from peers' assessment and feedback.

Finally, wikis allow students to edit and synthetize content associated with a specific topic in teacher education that is aligned with a given curriculum. Wikis can include content from written textbooks, but also online study material, for example links to information on Wikipedia and other Web sites. Wikis can be created to support all educational levels in teacher education and specific parts of a given subject. Focusing on the content element can not only stimulate students to engage in the creation of user-oriented wikis, but also motivate them to collaborate, discuss, and reflect on important issues of the wiki content and technicalities.

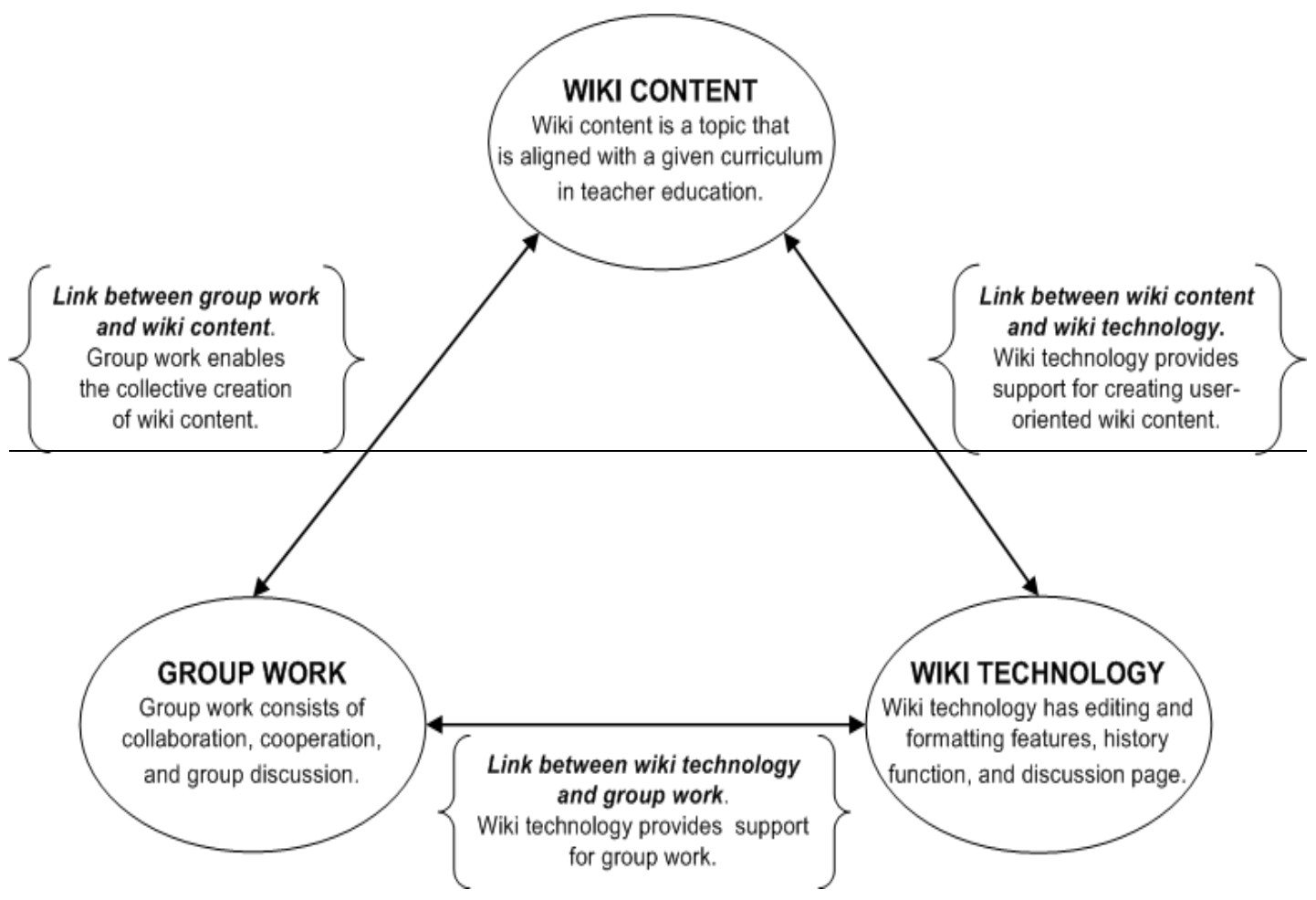

Figure 1: Key elements of wikis and their relationships in teacher education

\section{Evaluation Criteria}

Given the key elements of wikis and their relationships, it is possible to identify the criteria that can be used to assess students' perceptions of wiki-based collaborative writing. Hence, each key element is broken down into a set of specific criteria that are used to evaluate wiki-based collaborative writing in teacher education. 


\section{Wiki technology}

In line with Nielsen's principles of Web usability (Nielsen, 2000), the technological element of wiki, also called "Wiki usability" according to Mindel and Verma (2006), refers to the extent to which a wiki is convenient, practicable, and usable. This element can be broken down into four criteria:

\section{- Ease-of-use}

This criterion describes the extent to which the wiki is easy to use. Ease-of-use is also a function of the wiki tool being used, internet connection, and speed of page access.

\section{- Added value}

Added value is a criterion that is used to assess the potentialities of wikis to support collaborative writing and group work in comparison to similar technologies, such as Google Docs.

- Technical design

Technical design is concerned with the technical layout of the wiki, use of images, figures, tables, and lists, including formatting, and how the wiki as a whole is technically designed.

\section{- Navigation}

This criterion describes the navigation through the wiki in terms of number of wiki pages, internal and external links, and how easy it is to navigate through the wiki.

\section{Wiki content}

The content element is refined to realize two specific criteria: content understandability and content adaptability.

\section{- Content understandability}

This criterion reflects the way wiki developers create the content so that it is understandable for users. More specifically, this criterion describes the extent to which a user of a wiki understands the content and finds multiple ways to navigate through it. To be understandable, the wiki content should provide a well-structured description of the subject information using a clear and easily understandable language.

- Content adaptability / user-orientation In close connection with the understandability criterion, the wiki content needs to be adapted to the specific characteristics of the users, such as learning styles and prior knowledge. With other words, the wiki needs to be user-centred, enabling users to control themselves how to learn, explore and navigate through the wiki content based on their needs.

\section{Group work}

Wikis are considered as Web 2.0 tools that provide support for group work. Fostering group work is creating an environment that enables collaboration among participants. In addition, group work can take the form of discussion and critical reflections.

\section{- Collaboration}

A special form of collaboration is cooperation, which is simply splitting up the wiki topic into subtasks, and letting the students work independently of each other (Witney \& Smallbone, 2011). The wiki is then used to coordinate and assemble students' individual contributions to a final product. In contrast, genuine collaboration is accomplishing a task collectively (L. Grant, 2009; Mindel \& Verma, 2006; Trentin, 2009). It is more challeng- 
ing than cooperation, because it requires the mutual engagement of all participants in the collective development of the wiki (Chao \& Lo, 2011).

\section{- Discussion}

The criterion describes the extent to which the discussion page of the wiki is used to reflect on the wiki topic, and the way the content is designed to make it comprehensible to users. The subject of discussion may also be the functionalities of the wiki tool being used, and how these can support the representation of the content. Finally, highly valued discussion issues are reflections on the usefulness of information, critical review of literature, adaptation of language to users' characteristics, and revisions of each other's contributions to the wiki.

\section{Case Study}

This work adopted a case study approach to assess the students' perceptions of wikis when performing collaborative writing tasks in teacher education. The units of study were wikis that small groups of students created using the MediaWiki tool.

\section{Participants and Wiki Projects}

Sixteen teacher students were enrolled in a course on Web 2.0 technologies. Data from came from six groups of 2-4 students involved in developing wikis for topics related to teacher education that can be taught in schools (Geography, history, literature, religion, and technology). None of them experienced wiki before taking the course, but most of them had pedagogical background in teacher education and some technical skills in Web design. All students had experience with working in groups, and opted to choose their own partners. However, none of them experienced collaborative writing using wikis. Each group of students had to select a topic and work out a short document presenting their ideas on how the wiki projects should be performed. After receiving feedback from the instructor, the first drafts of the wikis were developed, and revised iteratively until the final wiki products were delivered. Although the students were assessed as a group rather than individually, it was stressed that individual engagement in the group was important to produce a wiki of good quality. However, the focus was on the groups themselves, since individual contributions were not graded. To ensure that a sufficient amount of writing is produced within the project period of 8 weeks, the students were required to deliver a wiki with at least 4000 words. Supervision was provided on regular basis to ensure that the wikis meet predefined requirements.

\section{Methods}

To evaluate students' perceptions of wiki-based collaborative writing using the criteria derived from the key elements of wikis, particular attention was devoted to the following data collection methods and their combination:

a) Peer-assessment to evaluate each other's wikis using a set of predefined criteria

b) Self-assessment to evaluate their own wiki based on a set of predefined criteria

Peer-assessment requires students to critically evaluate their peers by providing comments, making independent judgements based on clear criteria, identifying any deviations from the criteria, and providing suggestions for improvements. Peer-assessment helps students to understand their own wiki by means of feedback they receive from their peers (Vu \& Dall'Alba, 2007). This assessment form can enhance collaboration between students, "so that the feedback provided is appropriate and meaningful" (Vu \& Dall'Alba, 2007, p. 542). 
Self-assessment is similar to peer-assessment. The difference is that students assess their own wiki individually using an established set of explicit criteria. Self-assessment encourages students to judge and reflect on the quality of their own wiki, their role and contribution to group work. In educational settings, self- and peer-assessment may be linked to each other (Liu \& Carless, 2006). Self-assessment can be enhanced by peer-assessment in terms of feedback and constructive comments.

Both self- and peer-assessment were performed using a questionnaire with open-ended questions. Self-assessment used 13 statements, while peer-assessment was based on 7 statements. Both instruments were categorized by wiki technology, wiki content, and group work, and associated evaluation criteria. The results of self- and peer-assessment were then analysed quantitatively and interpreted qualitatively. In addition, the students were asked to respond to two open-ended questions and comment what they liked and disliked about the wikis, and what they think should be improved.

To measure their responses, self-assessment used a five-point Likert scale from 1 to 5, where 1 was coded as the highest and 5 as the lowest ( $1=$ "STRONGLY AGREE"; 2 = "AGREE"; $3=$ "NEITHER AGREE OR DISAGREE"; 4 = "DISAGREE"; 5= "STRONGLY DISAGREE"). Similarly, to assess the degree of agreement with a set of statements, peer-assessment used a fivepoint Likert scale from 1 to 5 with, where students' responses were coded as follows: $1=$ "VERY HIGH"; 2 = "HIGH"; 3 = "MIDDLE"; 4 = "LOW"; 5= "VERY LOW".

\section{Project Schedule and Development Approach}

The wiki projects ran at the beginning of the spring semester of the academic year of 2012. Students were asked to work in groups of 2-4 members, choose a particular topic within teacher education, and deliver a final wiki product. The procedure that was followed to produce the wikis consisted of 6 steps over a period of 8 weeks (Table 1):

\begin{tabular}{|c|c|l|}
\hline \multicolumn{3}{|c|}{ Table 1: Procedure for producing wikis } \\
\hline STEP & WEEK & \multicolumn{1}{|c|}{ ACTIVITIES } \\
\hline 1 & 1 & A short introduction to collaborative writing was given to the students \\
\hline 2 & 1 & Collaborative writing tasks were assigned to the student groups \\
\hline 3 & $2-8$ & Students developed their wikis in groups of 2-4 members \\
\hline 4 & $3-8$ & Teacher supervision \\
\hline 5 & 6 & Students performed peer-assessment using pre-established criteria \\
\hline 6 & 8 & Students self-assessed individually their own wikis using predefined criteria \\
\hline
\end{tabular}

Step 3 of the procedure used a rapid prototyping approach with 6 iterative phases to manage the development of the wikis: (a) Literature review; (b) Design of wiki structure; (c) Development of wiki content; (d) Integration; (e) Peer-assessment; (f) Self-assessment.

\section{Results}

\section{Self-Assessment}

Self-assessment used a survey questionnaire with 13 statements categorized by the key elements of wiki and associated criteria. Wiki technology is addressed by statement 1,2,3, and 4 (ease-ofuse, added value, technical design, and navigation). Wiki content is connected to statement 5,13 
(content understandability and adaptability). Finally, group work is covered by statement $6,7,8$, $9,10,11$, and 12 (collaboration and discussion).

The students were asked to respond to the survey using a Likert scale from 1 to 5 (STRONGLY AGREE, abbreviated as SA, AGREE (A), NEITHER AGREE OR DISAGREE (SAD), DISAGREE (D), and STRONGLY DISGAGREE (SD)). Table 2 shows the number of students who responded to each survey statement, including the average score (MEAN) and standard deviation (STDEV).

\begin{tabular}{|c|c|c|c|c|c|c|c|}
\hline \multicolumn{8}{|c|}{ Table 2: Results of self-assessment } \\
\hline STATEMENT & $\mathbf{S A}$ & $\mathbf{A}$ & NAD & D & SD & MEAN & STDEV \\
\hline $\begin{array}{l}\text { 1. MediaWiki is easy to use and } \\
\text { user friendly }\end{array}$ & 3 & 10 & 1 & 2 & 0 & 2.13 & 0.885 \\
\hline $\begin{array}{l}\text { 2. The wiki is easier to use than } \\
\text { other Web } 2.0 \text { tools }\end{array}$ & 0 & 0 & 12 & 4 & 0 & 3.25 & 0.447 \\
\hline $\begin{array}{l}\text { 3. The wiki is technically well } \\
\text { designed }\end{array}$ & 3 & 9 & 4 & 0 & 0 & 2.06 & 0.680 \\
\hline $\begin{array}{l}\text { 4. The navigation through the } \\
\text { wiki is easy }\end{array}$ & 6 & 10 & 0 & 0 & 0 & 1.62 & 0.500 \\
\hline $\begin{array}{l}\text { 5. The content of the wiki is } \\
\text { understandable }\end{array}$ & 6 & 8 & 2 & 0 & 0 & 1.75 & 0.683 \\
\hline $\begin{array}{l}\text { 6. MediaWiki supports collabo- } \\
\text { ration and discussion }\end{array}$ & 4 & 10 & 3 & 0 & 0 & 1.87 & 0.619 \\
\hline $\begin{array}{l}\text { 7. I like editing peers' contribu- } \\
\text { tions }\end{array}$ & 1 & 6 & 9 & 0 & 0 & 2.50 & 0.632 \\
\hline $\begin{array}{l}\text { 8. I like that peers edit my own } \\
\text { contributions }\end{array}$ & 5 & 7 & 4 & 0 & 0 & 1.94 & 0.772 \\
\hline $\begin{array}{l}\text { 9. The wiki topic stimulates } \\
\text { collaboration }\end{array}$ & 4 & 10 & 2 & 0 & 0 & 1.88 & 0.619 \\
\hline $\begin{array}{l}\text { 10. The wiki topic stimulates } \\
\text { discussion }\end{array}$ & 0 & 11 & 4 & 0 & 1 & 2.44 & 0.814 \\
\hline $\begin{array}{l}\text { 11. The level of collaboration is } \\
\text { high }\end{array}$ & 4 & 7 & 4 & 1 & 0 & 2.13 & 0.885 \\
\hline $\begin{array}{l}\text { 12. The level of discussion is } \\
\text { high }\end{array}$ & 2 & 6 & 6 & 2 & 0 & 2.50 & 0.894 \\
\hline $\begin{array}{l}\text { 13. The wiki is adapted to the } \\
\text { users' characteristics }\end{array}$ & 2 & 7 & 7 & 0 & 0 & 2.31 & 0.704 \\
\hline
\end{tabular}

\section{Wiki technology}

As Table 2 shows, there was little disagreement among students regarding wiki technology, with a vast majority indicating overall agreement, except for the criterion for added value (statement 2 ), which in contrast indicates a students' response close to neutrality or even disagreement. This is reflected in the average score obtained (MEAN=3.25, STDEV=0.447). In addition, the standard deviation is not very significant, except for statement 1,11 , and 12 . However, responses to openended questions show a slightly different picture. Indeed, some students were not satisfied with the MediaWiki tool as these representative students' comments clearly reveal:

"Old fashioned" user interface in the MediaWiki tool.

Could include simpler design features. In addition, I don't think that the edit function was very user friendly. If you have a lot of text, it can be confusing for some users to find their way to the right place. 
There is a learning threshold to use the MediaWiki tool. I think users can use such a tool if they do not have to code different things, such as tables. MediaWiki tool should be developed in the direction of being able to offer a WYSIWYG interface.

Some students focused on the lack of functionality that would make MediaWiki more usable and user friendly. They preferred to have more options for the design of the wiki:

What I did not like was that it gives few opportunities to show what they have changed-or see what other members have actually changed.

I think that they should develop a page for viewing (so everyone can see it) and a developer side (as they are editing the page you actually see) - so you can select the new text in a different color on the developer page for example.

It could have been a kind of toolbar where one could see the characters one should use (bold, line breaks, the size of images, text, etc...).

A little bit difficult to insert tables and (...) to post pictures.

\section{Wiki content}

Table 2 indicates that the overwhelming majority strongly agreed or agreed with the statement "The content of the wiki is understandable" (MEAN=1.75, STDEV =0.683). In some contrast, the statement "The wiki is adapted to the users' characteristics" obtained a slightly lower, but acceptable, score for more than the majority of the students (MEAN=2.31, STDEV=0.704). Students did not comment much this issue, but some responses are globally in line with the quantitative data:

Viewing the user group that has been set up on us, "All". It is impossible to make something to suit all.

There is a lot of information, although it might have been more. We have put emphasis on the things that are popular, and to some extent, hard facts.

Parts of the wiki are easy to understand, but something is written with a bit of "adult" language in relation to the target audience. The theme we have chosen has not so much to do with the students' interests, but it is still a subject they are teaching (...)

\section{Group work}

As the survey questionnaire shows, group work can be influenced by several factors: students' willingness or ability to edit each other's contributions (statement 7 and 8), capabilities of the wiki tool to support collaboration (statement 6), and the attractiveness of the wiki topic (statement 9 and 10). The history function expresses the level of collaboration (statement 11). Likewise, comments posted on the discussion page are an indicator of the discussion level (statement 12).

Looking closely at the results, it appears that all these factors impacted collaboration. Regarding the statement "I like that peers edit my own contributions", the score indicates strong agreement or agreement for most students (MEAN=1.94, STDEV=0.772), while the statement "I like to edit peers' contributions" obtained an average score (MEAN=2.50, STDEV $=0.632$ ), indicating that more than $50 \%$ of the students neither agreed nor disagreed with the statement. Likewise, most students strongly agreed or agreed that the wiki topic stimulates collaboration (MEAN $=1.88$, STDEV=0.619). In comparison, the statement "The wiki topic stimulates discussion" obtained an average, but acceptable score (MEAN=2.44, STDEV=0.814), since 11 students agreed with the statement. While the level of collaboration can be considered as satisfactory for more than the majority of the students (MEAN $=2.13, \mathrm{STDEV}=0.885$ ), the level of discussion is slightly lower, but acceptable for half of the students $(\mathrm{MEAN}=2.50, \mathrm{STDEV}=0.894)$. Finally, the students 
globally agreed or strongly agreed that MediaWiki supports collaboration and discussion $(\mathrm{MEAN}=1.87, \mathrm{STDEV}=0.619)$.

Feedback from students to open-ended questions provided useful and thoughtful comments, and a slightly different picture, in particular regarding the difficulty of collaborating and discussing using MediaWiki. Responses also reveal that some students still preferred to communicate verbally and face-to-face:

I think it was a bit artificial to work through the discussion forum, especially when we sit close to each other. However, we have tested it out, and it is probably a great tool if you work with people you do not meet very often.

We took some decisions about how to design the wiki in the discussion page. Yet I must admit that several of the decisions were taken face to face.

Had we been more in the group it would probably come more clearly. We worked together often in the lab, but the little that was done at home worked well through discussion.

It is an important part of the work, but not something I thought was particularly exciting (...).

It is not particularly critical, but somewhat reflective (...). The content was rarely debated.

It is necessary for peers to comment on contributions, but I think it may be more useful to do this verbally than in the discussion page. Then you can make yourself more easily understood.

We have enough commented and discussed each other's work more critical and reflective than on the discussion page.

In addition to the discussion page, students were also critical regarding the way they collaborated as the following comments clearly reveal:

We could have worked more on the page, and talked more together. I could even have contributed more with written content, images and tables.

The wiki quickly becomes more like an encyclopedia, in which facts are a top priority. Ifeel that to the extent we have been working with it (...), there has been little interest in discussing the substance, more than what each one should do.

The starting point was that we would rather have been 3 in the group, but since one chose to give up, the degree of collaboration was not particularly good. We used the discussion forum, in the latter phase, when we worked by ourselves.

Collaboration has been the main focus of the wiki. I feel that I should have done more.

\section{Peer-Assessment}

As for self-assessment, peer-assessment was categorized by wiki technology, wiki content, and group work. These were themselves categorized in 7 criteria (Table 3). To address the issue of wiki technology, the students were asked to assess the level of technical design and navigation (statement 1 and 2), followed by the criteria of content understandability and adaptability, or userorientation (statement 3 and 4). Finally, peer-assessment addressed the issue of collaboration and discussion associated with group work (statement 5 and 6).

The students were asked to measure the level of agreement using a Likert scale from 1 to 5 (VERY HIGH, HIGH, MIDDLE, LOW, and VERY LOW). Table 3 shows the number of students who responded to each survey statement, including the average score (MEAN) and standard deviation (STDEV). 


\begin{tabular}{|l|r|r|r|r|r|r|r|}
\hline \multicolumn{7}{|c|}{ Table 3: Results of peer-assessment } \\
\hline STATEMENT & $\begin{array}{r}\text { VERY } \\
\text { HIGH }\end{array}$ & HIGH & MIDDLE & LOW & $\begin{array}{r}\text { VERY } \\
\text { LOW }\end{array}$ & MEAN & STDEV \\
\hline $\begin{array}{l}\text { 1. Level of technical } \\
\text { design }\end{array}$ & 1 & 7 & 6 & 2 & 0 & 2.56 & 0.814 \\
\hline $\begin{array}{l}\text { 2. Level of naviga- } \\
\text { tion and linking }\end{array}$ & 0 & 5 & 9 & 2 & 0 & 2.81 & 0.655 \\
\hline $\begin{array}{l}\text { 3. Level of content } \\
\text { understandability }\end{array}$ & 0 & 6 & 7 & 3 & 0 & 2.81 & 0.750 \\
\hline $\begin{array}{c}\text { 4. Level of content } \\
\text { adaptability }\end{array}$ & 0 & 4 & 7 & 5 & 0 & 3.06 & 0.772 \\
\hline $\begin{array}{c}\text { 5. Level of collabora- } \\
\text { tion }\end{array}$ & 0 & 7 & 6 & 3 & 0 & 2.75 & 0.775 \\
\hline $\begin{array}{c}\text { 6. Level of discus- } \\
\text { sion }\end{array}$ & 0 & 5 & 3 & 8 & 0 & 3.19 & 0.911 \\
\hline
\end{tabular}

\section{Wiki technology}

Responses to peer-assessment reveal that half of the students were very satisfied or satisfied with the technical design of the wikis in terms of layout, inclusion of figures, images, lists, colours and tables (MEAN=2.56, STDEV=0.814). In contrast, only 5 students found that the level of navigation through the wiki was satisfactory $(\mathrm{MEAN}=2.81$, STDEV=0.655). Comments to open-ended questions referred mostly to key words to be linked and navigation, e.g., key words that were not linked at all or linked to empty sides, misuse of colours, inappropriate choice of links, lack of key words and figures, multiple linking of the same key word, and poor design of tables. Some of the representative comments are:

Some key words are obviously not properly linked (...) and that there is no link in the words. I would have tried to include some more links (...).

The links are empty and therefore they have no value: All links lead to pages without content. There are no links for keywords in subsection 3. There are many keywords for 3 sections that should be explained.

Easy to follow the links, but the external links should have a name and an "invisible" URL. With other words, the links need an appropriate description. Otherwise, there are many keywords that are linked up, and do not have content.

The internal links are okay, but there are a couple of keywords that should be linked.

I miss the link back to the main page in some of the pages.

As previously mentioned, I think that the page can be improved by a little more variety in graphic illustrations, and change the sentence structure here and there.

\section{Wiki content}

Concerning content understandability, six students indicated that the wiki content was easy to understand (MEAN=2.81, STDEV=0.750). In some contrast, only 4 students agreed that the wikis were well adapted to the users' characteristics, and 7 students believed that adaptability of content was of average quality (MEAN=3.06, STDEV=0.772). These are typical students' comments:

I think the language is a bit difficult considering that the target audience is $5-7^{\text {th }}$ grade. 
Not everything was easy to understand, thinking particularly of young students who will read this.

For me, the content is understandable and interesting, but for children of 5-7age, there are maybe too many figures and dry facts that they can familiarize themselves with them.

The wiki does not define what is meant by the various terms, therefore, the wiki will be aimed at professionals in the field.

The wiki lacks a defined purpose; it should come out more clearly who the target group is.

I cannot see that you have defined the target group. Thus, I assume that it is intended for 'all'.

Maybe, it is not accurately adapted for children, since there are some concepts that can be difficult for them and young people.

But, you can probably miss the youngest age group, if you use adult concepts.

\section{Group work}

Regarding group work, the results show that 7 students were satisfied with the level of collaboration, without giving any further explanation in their feedback to open-ended questions (MEAN=2.75, STDEV=0.775). However, it is difficult to interpret the students' responses, as it is not clear what they meant with "collaborating with other", even though 5 students responded that the history function showed a high level of collaboration. However, from the history function it is difficult to draw conclusions that students really collaborated, without a detailed analysis of students' contributions. Only one student was aware of the fact that it is difficult to interpret the quality of collaboration. Claiming that the level of collaboration was high without any further explanation does not imply that the students edited each other's contributions. It is possible that they cooperated rather than collaborated. Regarding discussion, it appears that the responses were even more negative than those expressed for collaboration, since half of the students indicated that the level of discussion was low $(\mathrm{MEAN}=3.19, \mathrm{STDEV}=0.991)$.

Comments and responses to open-ended questions support the quantitative results. Some students emphasized the role of the history function:

Judging from the history function, it seems that everyone has contributed equally.

It seems that only one student has been responsible for the content if you follow the history of contribution. It is however possible that the students were working together under a single user.

It is difficult to interpret the quality and extent of collaboration based only on the history function, but it seems that everyone has contributed and that the group has worked steadily.

It does not look like there has been no communication via the discussion page, but it is so far understandable if one is working on the lab. History shows that it has been working well.

The history function clearly shows that you have worked with each other's pages. That is okay, though you might have shared the first page.

Other students indicated that collaboration worked well without giving any further explanation of the way they worked together. Hence, it is not clear whether they collaborated or cooperated.

You have many pages, but it appears that you have helped each other. You have divided the pages among yourselves, and collaboration is high.

The degree of collaboration is high. It seems that you have worked and contributed well. It looks like everyone has been active and worked with the wiki. 
There was not much discussion in the group (...), but it must have taken place outside the discussion page of the wiki in that case (...)

It looks like everyone has contributed.

It seems that the group has worked well! This is also evident from the discussion page.

\section{Discussion}

First, a brief summary of the results related to research question 1 and 2 is given. To address the third research question, pedagogical implications are drawn from the results. Then, a wiki pedagogy that fosters collaborative writing with wikis is suggested. The limitations of the work are addressed as well.

\section{Key Elements of Wikis and Their Relationships}

This work identified three key elements of wikis that are important in teacher education: wiki technology, wiki content, and group work. These elements need to be connected to each other in order to provide opportunities for collaborative writing. Three bi-directional connections or links are formed between the key elements. The first connection is between wiki technology and wiki content. The second one is between wiki technology and group work. Lastly, it is important to link wiki content and group work.

\section{Students' Perceptions of Collaborative Writing}

Both self- and, to a lesser degree, peer-assessment indicate that the wikis were technically well designed in terms of layout, figures, images, and formatting. Regarding navigation, selfassessment shows a high level of navigability, in stark contrast to peer-assessment which indicates a rather average navigability level and linking. In any case, students' responses to openended questions reveal that MediaWiki lacks advanced functionality and a WYSIWYG editor to support the design of usable and user-friendly wikis.

Concerning content understandability, both self- and peer-assessment, indicate a satisfactory level of understandability. Likewise, self-assessment shows a satisfactory level of adaptability, in contrast to peer-assessment, which indicates a lower degree of adaptability. In any case, responses to open-ended questions by means of peer-assessment reveal that the wikis were not well adapted to the users' characteristics, while self-assessment was slightly more positive.

Regarding group work, self- and peer-assessment indicate that the level of collaboration was satisfactory, in contrast to discussion, which achieved a lower result. However, it is difficult to interpret the quantitative results achieved for collaboration based on Likert scales. Five students referred in peer-assessment to the history log to support their views, but it is not easy to draw conclusions from the log that students really collaborated, without a detailed analysis of students' contributions. It is possible that they cooperated rather than collaborated. Indeed, responses to open-ended questions reveal the difficulty of collaborating, because collaborative strategies were not evident in their comments. The students also raised the difficulty of using the discussion page for reflections, and that oral communication was still important.

As a result, there is no clear evidence that the relationships between wiki content, wiki technology, and group work were strengthened through the use of wikis in 8 weeks. Rather, it appears that wiki affordances and potentialities were not fully used to achieve a good level of collaboration, discussion, and content adaptation. The poor connectedness of wiki content and group work, on the one hand, and wiki content and technology, on the other hand, may be explained by the hypothesis that students did not fully take advantage of MediaWiki functionality, or that the existing functionality does not fully support collaboration and design of user-oriented content. Like- 
wise, the poor connectedness of content and group work can be explained by the fact that students lacked collaborative skills. Additional factors, which were not considered in the theoretical framework, may have influenced collaborative writing.

\section{Pedagogical Implications}

The implications are analysed in terms of the theoretical framework and its main elements. To this end, the framework was used to inform the study, and the results were mapped back onto the framework in order to analyse the impact of the basic elements of wikis on each other, on the one hand, and identify additional factors that may influence collaborative writing in teacher education, on the other hand.

\section{Wiki technology and wiki content}

When evaluating the impact of the wiki technology being used on wiki content, the results show that the participating students used a small set of technical features to design the wikis, and focused mainly on understanding these features, and commenting the way they used them, such as insertion of figures, tables, and images, formatting pages, making links to new pages, etc. Even though most students did not encounter major technical difficulties in developing the wikis, it is obvious that the current wiki platform needs to be improved to include extended functionality that facilitates editing and technical layout. There is also a general agreement that there is a need for a WISIWYG editor that ensures a trouble-free interaction with the tool (Thomas, King, \& Minocha, 2009). Such an editor would help to minimize students' cognitive load, resulting from the interaction with the wiki tool in order to free more resources for the collaborative creation of content. Furthermore, students need basic skills in Web design to create more usable wikis. Additionally, criteria that influence the pedagogical usability of WBLRs are as follows: technical issues such as login, losing of content, browser compatibility, and server connection were sometimes a source of frustration for students, in accord with previous research (Every, Garcia, \& Young, 2010; Jones, 2010). These technical problems are not exclusively the result of the particular wiki tool being used in this work, that is MediaWiki, but are common to many other tools used in various educational setting as the research literature shows (Elgort, Smith, \& Toland, 2008; Jones, 2010; Harsell, 2010; Thomas, King \& Minocha, 2009).

\section{Collaboration and wiki content}

In order to design a wiki for a given topic that fulfils quality criteria and specific characteristics of users, students in the groups need to be knowledgeable in the wiki topic being studied, and how to organize central facts and ideas of the topic to foster meaningful understanding. Students lacking this basic knowledge can misrepresent the wiki topic, unless they are able to collaboratively address potential misconceptions associated with the characteristics of the users. However, an analysis of the wikis shows that the students did not identify gaps in their knowledge to make their wiki topic more relevant and attractive for the users. Rather, the students focused more on selecting content from Wikipedia and other Web sites rather than developing knowledge that suits the target audience. In addition, the content produced seems to be limited to each individual student, rather than shared with the group. To support collaboration, appropriate incentives that counter-balance those focusing on individual work need to be introduced. In this regard, motivational factors may play an important role in creating content of good quality. Motivation is a function of the value a student places on the wiki content, whether it is enjoyable and contains information that is specifically relevant to the student (Davidson, 2012). Clearly, motivation may affect the amount of collaboration a student is willing to invest in working together with peers in creating the wiki content. 


\section{Wiki technology and discussion}

A content analysis of the discussion page shows that the students did not address the usefulness of wiki content and literature, user-orientation, and collaboration issues, except suggestions related to technological aspects of the wiki, such as formatting, wiki length, and addition of content to existing pages. In their responses to open-ended questions, some students reported that they still valued oral communication and face-to-face meetings for taking decisions. Since students still like to communicate face-to-face with their peers, and sometimes by other channels, such as mobile phone and email, it would be difficult for the teacher to limit students' discussions to the wiki tool. Hence, face-to face interactions and use of other communication channels cannot be ignored in collaborative writing (Ferris \& Wilder, 2006). One possible explanation for increased face-toface discussion and verbal communication is that the current version of MediaWiki does not have advanced functionality that enables discussions without writing down the date of contribution and name of contributor. Comments and suggestions without author's name and date clearly disturb the flow and quality of discussions. Hence, MediaWiki in its present form, alone without the use of other tools and face-to-face meetings, is not appropriate to support critical discussion and reflections. As a result, it appears that while wikis may facilitate group work, in-depth discussions among students are not supported by the technology.

\section{History function and assessment of collaborative writing}

Both self- and peer-assessment reveal that students had difficulties distinguishing between cooperation and collaboration. Indeed, while most students felt that they liked editing each other's contributions, few edited material from other group members, in line with the results of previous research work (Forte \& Bruckman, 2007; L. Grant, 2009; Lund \& Smørdal, 2006). As a result, individual work was more evident by dividing up the wiki task into subtasks that are developed individually. Group size did not impact much collaborative writing as similar research reveals (Hadjerrouit, 2013; Leung \& Chu, 2009). Likewise, Judd, Kennedy, and Copper (2010, p. 346) indicate that "the degree to which students contributed to the task varied considerably, with a relatively small number of students contributing most of the wiki content". Individual work clearly limits the creation of shared knowledge. One explanation is that students appeared to use practices of individualised work to which they were accustomed, rather than really collaborating to realize shared knowledge (L. Grant, 2009). Another explanation is due to the assessment form which may influence students' way of working (Tetard et al., 2009). Since the students were not assessed individually, but as a group, they preferred cooperation rather than collaboration, which is more challenging and demanding in terms of time and efforts. Moreover, the wiki history function seems to confirm that the students approached the collaborative writing tasks more cooperatively than collaboratively, and that few students actively collaborated to construct shared knowledge. The advantage of the history function is that it is inherently more reliable to assess students' contributions to the wiki than qualitative methods. It can be used to create quantitative data to assess the level of contribution, type of activities carried out on the wiki, timing of contribution, and work intervals (Hadjerrouit, 2013; Harsell, 2010; Judd et al., 2010).

\section{Peer-assessment and wiki content}

Looking at the final wiki products, it appears that peer-assessment had some positive impact on the quality of the wikis in terms of technical design, content, and collaboration. This is clearly a benefit. However, the quality of feedback from peers varied, and was not considered as important as feedback from the teacher. Indeed, it was the teacher who challenged the students to thoroughly consider feedback from peers, and make constructive use of their suggestions. This does not mean that the students did not benefit from peer-assessment, but the teacher's role seems to be critical. Hence, to be effective peer-assessment requires not only a thorough preparation, such as defining the evaluation criteria and enhancing students' awareness of the benefits of this as- 
sessment form, but also teacher's assistance throughout the whole wiki creation process. Finally, the results indicate that students were more critical when they evaluated their peers than selfassessing their own wikis. Hence, it is important to encourage peer-assessment, since it provides more critical comments and constructive suggestions than self-assessment.

\section{Wiki Pedagogy}

This work reveals that a number of influencing factors need to be considered to engage students in collaborative writing ( $\mathrm{Li} \& \mathrm{Zhu}, 2013$ ). Firstly, students need to be familiar with the wiki topic and users' specific characteristics and motivated to engage in the design of user-oriented wikis. Then, students need to be aware of wiki affordances to support the writing process in terms of simplicity, flexibility, and accessibility to study material that suits the wiki topic. Knowledge, techniques, and guidelines in Web design and usability issues are also important pre-requisites. In addition, group work skills in terms of collaboration and discussion with peers are important to carry out collaborative writing. Furthermore, the assessment of students' contributions, which can take many forms, needs to be emphasized to foster collaborative writing and reciprocal interaction (Li \& Zhu, 2013; Tetard et al., 2009). Assessment is important, because the quality of a wiki depends on the way students are assessed: individually, as a group, or both. Another factor that impacts collaborative writing is time (Caple \& Bogle, 2013). Writing collaboratively is time intensive as it is cognitively demanding in terms of writing, revising, searching for information, reflecting on ideas, and structuring the information to an overall wiki (Harsell, 2010).

It implies from these considerations that wiki technology alone does not make collaboration automatically happen (M. M. Grant \& Mims, 2009; Pifarré \& Fisher, 2011). Beyond technology, it may be necessary to thoroughly address the wiki content and the approach being used by groups of students to create it. Clearly, collaborative writing cannot be successful without strengthening the relationships between the wiki topic, wiki technology, and group work. According to Huang and Nakazawa (2010), and Ferris and Wilder (2006), the process of creating wikis needs to be carefully planned and managed by a sound pedagogy to sustain students' activities such as writing collaboratively, critically reviewing each other's contributions, and revising content throughout the wiki creation process. Embedding a suitable pedagogy into the wiki development process is crucial to minimize the barriers to successful collaborative writing (Every, Garcia, \& Young, 2010; Li \& Zhu, 2013; Witney \& Smallbone, 2011). A pedagogy that suits wikis in teacher education requires a thoughtful interweaving of content, technology, and group work. Technical features of wikis do not need to be learned separately from collaborative writing and content design. On the contrary, according to Mishra and Koehler (2006), students have to actively engage in design practices, inquiry, and research in collaborative groups as they use wiki technology. The role of the instructor is that of a facilitator of collaborative learning rather than an expert of wiki content. The proposed wiki pedagogy starts from considering content, technology, and group work as separate variables toward a gradual integration and a deeper understanding of the complex relationships between these elements. The main steps of the pedagogy, which may vary slightly from case to case, are:

1. Introduce the wiki project to the students, its objectives, goals, time schedule, and deadlines.

2. Discuss rules for participating in collaborative work with wikis, including strategies for small groups, and roles for the participants. Explain the difference between cooperation and collaboration. Make the students aware of the role of assessment.

3. Let the students choose a wiki topic for a specific target audience.

4. Provide selected wiki applications and good examples of wiki in teacher education, and guidelines for facilitating the creation of wikis. Discuss usability issues needed to design comprehensible, motivating and user-oriented content. 
5. Introduce the wiki tool to be used, and discuss wiki affordances in terms of simplicity of technical design, editing each other's content, history function to track different versions of the wiki, and discussion page. Let students use the tool.

6. Introduce the students to an overall strategy for developing wikis, similar to the one presented in this work, by first splitting up the wiki in subtasks that are assigned to each student, and gradually integrating them collaboratively to an overall wiki throughout the stages of the development process. Let students create content for each task, including figures, images, tables, etc.

7. Let students construct the first draft of the wiki.

8. Continue developing the wiki by applying the development strategy.

9. Focus on integrating the different parts of the wiki to fit together smoothly.

10. Perform peer-assessment based on predefined criteria.

11. Perform self-assessment using similar criteria.

\section{Limitations}

Since this study used a small convenient sample with only one class $(N=16)$, it is difficult to generalize to other classes, even though the result are in accord with some previous research findings. Nevertheless, the results of the survey questionnaires are difficult to interpret, without drawing on comments to open-ended questions. Self-assessment based on predefined criteria is an appropriate method that provides opportunities for students to become actively involved in the evaluation of their own wikis. Self-assessment helps to promote critical thinking and encourage responsibility for learning from their failures (Carr, 2011). To be effective, this method should provide good examples of self-assessment. Likewise, peer-assessment based on pre-established criteria is a powerful technique to assess peers' work by providing constructive comments, even though some students dislike evaluating their peers (Liu \& Carless, 2006). However, planning and teacher's assistance are required to make students aware of the potential benefits of peer-assessment (Topping, 2009). According to Cowan (2010), it is important for both self- and peer-assessment to use criteria that have been previously discussed with the students. Finally, supplementary data collection methods such as focus groups and interviews may increase the degree of reliability and validity of the results.

\section{Conclusions}

Training students to acquire basic competency in using wiki technology is simply not sufficient to succeed in collaborative writing. Rather, collaborative writing requires a thoughtful understanding and interweaving of the complex relationships between wiki technology, wiki content, and group work. This implies the development of a theoretical framework of technology, content and group work that informs teachers and researchers conducting empirical studies on wikis. Furthermore, collaborative writing cannot be successful, unless students are actively engaged in practices of enquiry, wiki design and development in collaborative groups. This work is an attempt to use this theoretical framework to assess students' perceptions of collaborative writing activities associated with a given topic in teacher education. Based on the results, pedagogical implications are suggested that may be used by teachers to successfully carry out wiki-based collaborative writing activities. Even though collaborative writing was not carried out as expected, the framework provides a promising way of investigating wiki-based collaborative writing in teacher education by looking at the relationships between wiki technology, content, and group work. Future work will explore the framework in more depth through iterative design of wikis to promote collaborative writing in teacher education. 


\section{References}

Austin, R., Smyth, J., Rickard, A., Quirk-Bolt, N., \& Metcalfe, N. (2010): Collaborative digital learning in schools: Teacher perceptions of purpose and effectiveness. Technology, Pedagogy and Education, 19(3), 327-343.

Caple, H., \& Bogle, M. (2013). Making group assessment transparent: What wikis can contribute to collaborative projects. Assessment \& Evaluation in Higher Education, 38(2), 198-210.

Carr, S. C. (2011). Self-assessment: Involving students in their own learning. Reading and Writing Quarterly: Overcoming Learning Difficulties, 18(2), 195-199.

Chao, Y-C. J., \& Lo, H-C. (2011). Students' perceptions of wiki-based collaborative writing for learners of English as a foreign language. Interactive Learning Environments, 19(4), 395-411.

Cole, M. (2009). Using wiki technology to support student engagement: Lessons from the trenches. Computer \& Education, 52, 141-146.

Cowan, J. (2010). Developing the ability for making evaluative judgments. Teaching in Higher Education, $15(3), 323-334$.

Davidson, R. (2012). Wiki use that increases communication and collaboration motivation. Journal of Learning Design, 5(2), 38-49.

Deters, F., Cuthrell, K., \& Stapleton, J. (2010). Why wikis? Student perceptions of using wikis in online coursework. MERLOT Journal of Online Learning and Teaching, 6(1), 122-134.

Elgort, I., Smith, A. G., \& Toland, J. (2008). Is wiki an effective platform for group course work? Australian Journal of Educational Technology, 24(2), 195-210.

Every, V., Garcia, G., \& Young, M. (2010). A qualitative study of public wiki use in a teacher education program. In D. Gibson, \& B. Dodge (Eds.). Proceedings of Society for Information Technology \& Teacher Education International Conference, 55-62.

Ferris, S., \& Wilder, H. (2006). Uses and potentials of wikis in the classroom. Innovate 2 (5). Retrieved, April 24, 2012 from http://www.innovateonline.info/index.php?view=article\&id=258

Forte, A., \& Bruckman, A. (2007). Constructing task: Wiki as a toolkit for (collaborative?) learning. Proceedings of the 2007 International Symposium on Wikis (WikiSym '07), Montreal, 31-42. Quebec, Canada. New York: ACM.

Goodsell, A., Maher, M., \& Tinto, V. (1992). Collaborative learning: A sourcebook for higher education. University Park: National Center on Postsecondary Teaching, Learning, and Assessment, Pennsylvania State University.

Grant, L. (2009). 'I don't' care do our own page!' A case study of using wikis for collaborative work in a UK secondary school. Learning, Media, and Technology, 34(2), 105-117.

Grant, M. M., \& Mims, C. (2009). Web 2.0 in teacher education: Characteristics, implications and limitations. In T. Kidd \& I. Chen (Eds.) Wired for learning: An educators guide to Web 2.0, 343-360. Charlotte, NC: Information Age Publishing. Retrieved, May 22, 2012 from http://dl.dropbox.com/u/34403200/articles/grant_mims web20 formatted.doc

Guerrero, L., Mejías, B. Collazosi, C. A., Pino, J. A., \& Ochoa, S. F. (2003). Collaborative learning in creative writing. Proceedings of the First Latin American Web Congress (LA-WEB 2003), 180-186.

Hadjerrouit, S. (2012a). Investigating technical and pedagogical usability issues of collaborative learning with wikis. Informatics in Education, 11(1), 45-64.

Hadjerrouit, S. (2012b). Wiki-based collaborative learning in higher education: A pedagogical Evaluation. International Journal of Innovation and Learning, 12(1), 6-26.

Hadjerrouit, S. (2012c). Pedagogical criteria for successful use of wikis as collaborative writing tools in teacher education. $20123 r d$ International Conference on e-Education, e-Business, e-Management and e-Learning. IPEDR, 27, 11-15. Singapore: IACSIT Press. 
Hadjerrouit, S. (2013). Collaborative writing with wikis: Pedagogical and technological implications for successful implementation in teacher education. In D. G. Sampson, P. Isaias, D. Ifenthaler, \& J. M. Spector, Ubiquitous and mobile learning in the digital age (pp. 173-189). New York: Springer.

Harsell, D. M. (2010). Wikis in the classroom: Faculty and student perspective. Journal of Political Science Education, 6(3), 310-314.

Hernandez, N., Hoeksema, A., Kelm, H., Jefferies, J., Lawrence,K., Lee, S-S., \& Miller, P. (2000). Collaborative writing in the classroom: A method to produce quality work. Retrieved, February 12, 2013 from http://www.edb.utexas.edu/cscl/2008/topicpapers/s2paper.pdf

Honegger, B. D. (2005). Wikis - A rapidly growing phenomenon in the German-speaking school community. Proceedings of WikiSym' '05, October 16-18, San Diego, CA, U.S.A.

Huang, W.-H.D., \& Nakazawa, K. (2010). An empirical analysis on how learners interact in wiki in a graduate level online course. Interactive Learning Environments, 18(3), 233-244.

Johnson, D. W., \& Johnson, R. T. (1985). The internal dynamics of cooperative learning groups. In R. Slavin, S. Sharan, S. Kagan, R. Hertz-Lazarowitz, C. Webb, \& R. Schmuck (Eds.), Learning to cooperate, cooperating to learn (pp. 103-124). New York: Plenum.

Jones, P. (2010). Collaboration at a distance: Using a wiki to create a collaborative learning environment for distance education and on-campus students in a social work course. Journal of Teaching in Social Work, 30(2), 225-236.

Judd, T., Kennedy, G., \& Cropper, S. (2010). Using wikis for collaborative learning: Assessing collaboration through contribution. Australasian Journal of Educational Technology, 26(3), 341-354.

Kasemvilas, S., \& Olfman, L. (2009). Design alternatives for a MediaWiki to support collaborative writing. Journal of Information, Information Technology, and Organizations, 4, 87-104. Available at http://www.informingscience.org/jiito/articles/JIITOv4p087-106Kasemvilas.pdf

Lamb, B. (2004). Wide open spaces: Wikis, ready or not. EDUCAUSE Review, 39(6), 36-48.

Leung, K., \& Chu, S. K.W. (2009). Using wikis for collaborative learning: A case study of an undergraduate students' group project in Hong Kong. Retrieved May 25, 2012 from http://www.ickm2009.org/snews/upload/ickm_2009

Li, M., \& Zhu, W. (2013). Patterns of computer-mediated interaction in small writing groups using wikis, Computer Assisted Language Learning, 26(1), 61-82.

Liu, N-F., \& Carless, D. (2006). Peer feedback: The learning element of peer-assessment. Teaching in Higher Education, 11(3), 279-290.

Lund, A., \& Smørdal, O. (2006). Is there a space for the teacher in a wiki? Proceedings of WikiSym'06, August 21-23, 2006, Odense, Denmark, 27-45.

Mindel, J. L., \& Verma, S. (2006). Wikis for teaching and learning. Communications of AIS, 18(1), 2-38.

Mishra, P., \& Koeler, M.J. (2006). Technological pedagogical content knowledge: A framework for teacher knowledge. Teachers College Record, 108(6), 1017-1054.

Ng, E. M. W., \& Lai, Y. C. (2012). An exploratory study on using wiki to foster student teachers' learnercentered learning and self and peer-assessment. Journal of Information Technology Education: Innovations in Practice, 11, 71-84. Available at http://www.jite.org/documents/Vol11/JITEv11IIPp071084NG1096.pdf

Nielsen, J. (2000). Designing Web usability: The practice of simplicity. Indianapolis, Indiana: New Riders.

Nokes-Malach, T. J., Meade, M. L., \& Morrow, D. G. (2012): The effect of expertise on collaborative problem solving. Thinking \& Reasoning, 18(1), 32-58.

Parker, K. R., \& Chao, J.T. (2007). Wiki as a teaching tool. Interdisciplinary Journal of Knowledge and Learning Objects, 3, 57-72. Available at http://www.ijello.org/Volume3/IJKLOv3p057072Parker284.pdf 
Pifarré, M., \& Fisher, R. (2011). Breaking up the writing process: How wikis can support understanding the composition and revision strategies of young writers. Language and Education, 25(5), 451-466.

Tay, E., \& Allen, M. (2011). Designing social media into university learning: Technology of collaboration or collaboration for technology? Educational Media International, 48(3), 151-163.

Tetard, F., Patokorpi, E., \& Packalen, K. (2009). Using wikis to support constructivist learning: A case study in university education settings. Proceedings of the 42nd Hawaii International Conference on System Sciences, 1-10.

Thomas, P., King, D., \& Minocha, S. (2009). The effective use of a simple wiki to support collaborative learning activities. Computer Science Education, 19(4), 293-313.

Topping, K. J. (2009). Peer-assessment. Theory into Practice 48(1), 20-27.

Trentin, G. (2009). Using a wiki to evaluate individual contribution to a collaborative learning project. Journal of Computers Assisted Learning, 25, 43-55.

Vu, T. T., \& Dall'Alba, G. (2007). Students' experience of peer-assessment in a professional course. Assessment \& Evaluation in Higher Education, 32(5), 541-556.

Vygotsky, L. S. (1978). Mind and society: The development of higher mental processes. Cambridge, MA: Harvard University Press.

Witney, D., \& Smallbone, T. (2011). Wiki work: Can using wikis enhance student collaboration for group assignment task? Innovations in Education and Teaching International, 48(1), 101-110.

Yarrow, F., \& Topping, K.J. (2001). Collaborative writing: The effects of metacognitive prompting and structured peer interaction. British Journal of Educational Psychology, 71(2), 261-282.

\section{Biography}

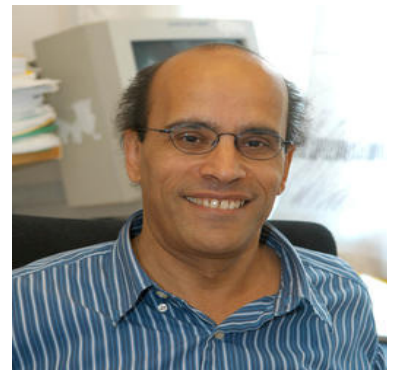

Said Hadjerrouit is a Full Professor of Informatics and Computer Science at the University of Agder. He holds a Ph.D. (1992) in Medical Expert Systems and Artificial Intelligence, and a Master (1985) in Software Engineering from the Technical University of Berlin (Germany). He has been working at the University of Agder since 1991. Hadjerrouit has teaching experience in informatics and society, philosophical and ethical issues of computing, object-oriented programming, Web engineering, software development, databases, didactics of informatics, ICT in mathematics education, and ICT-based learning. His current research focuses on software engineering education, didactics of informatics, ICT in mathematics education, e-Learning, technology-enhanced learning, Web-based learning resources, Web 2.0 technology, and social software. Hadjerrouit has published more than 110 articles in international journals and conferences proceedings. 